\title{
BURRICE CRESCE NA TV POR ASSINATURA ${ }^{1}$
}

\section{Serviço das operadoras precisa ser avaliado já ou será tarde demais}

A Comissão Federal do Comércio dos EUA, em decisão tomada no dia 18 de julho de 1996, condicionou a fusão da Time/Warner com a Turner a duas exigências: que a nova empresa disponibilize para os assinantes mais um canal de notícias para concorrer com a $\mathrm{CNN}$ e que os pacotes de programação sejam flexíveis, permitindo que o espectador compre apenas o que ele quer ver.

$\mathrm{O}$ fato é histórico. Pela primeira vez as autoridades americanas atrelam a criação de empresas de TV por assinatura a exigências de programação. A fusão da Time/Warner com a Turner (que controla redes de TV paga como a CNN, a TNT e a Cartoon Network) é um negócio de US\$ 8 bilhões, que vai formar a maior empresa de comunicações do mundo. Desde as megafusões deste último ano, que culminaram com a compra da $\mathbf{A B C}$ pela Disney, o mercado se preocupa com uma reversão nos princípios democratizantes que estavam no ideário desta nova forma de distribuir sinais de televisão. Na prática, um número cada vez maior de redes e operadoras está em mãos de um número cada vez menor de empresas.

O Brasil, como habitualmente, tem absorvido as piores lições e esquecido as boas. O mercado de TV por assinatura, que é uma criança de quatro anos, já começa a desenhar vícios de gente grande. O concentracionismo das operadoras foi assimilado por todo mundo, e não se fala mais nisso. Mas o serviço que elas estão prestando à sociedade tem que ser avaliado agora, antes que seja tarde demais. É mais fácil vencer um mau hábito hoje do que amanhã, já dizia Confúcio.

\section{O LIXO DA TV}

Para vender quantidade, as operadoras distribuem redes que em alguns casos thes custam menos de $\mathrm{R} \$ 0,05$ por assinante. São o lixo da TV por assinatura internacional, canais que não interessam a ninguém, mas que já chegam pagos ao Brasil e são despejados no pacote. Em pelo menos dois casos, a programação é entregue literalmente de graça às operadoras. Isso, em detrimento de três coisas: a demanda real do público, a segmentação, que justifica moralmente a

\section{O AUTOR \\ Nelson Hoineff \\ Jornalista, diretor de televisão e autor de TV em Expansão e A Nova Televisão - Desmassifica- ção e o Impasse das Grandes Redes.}




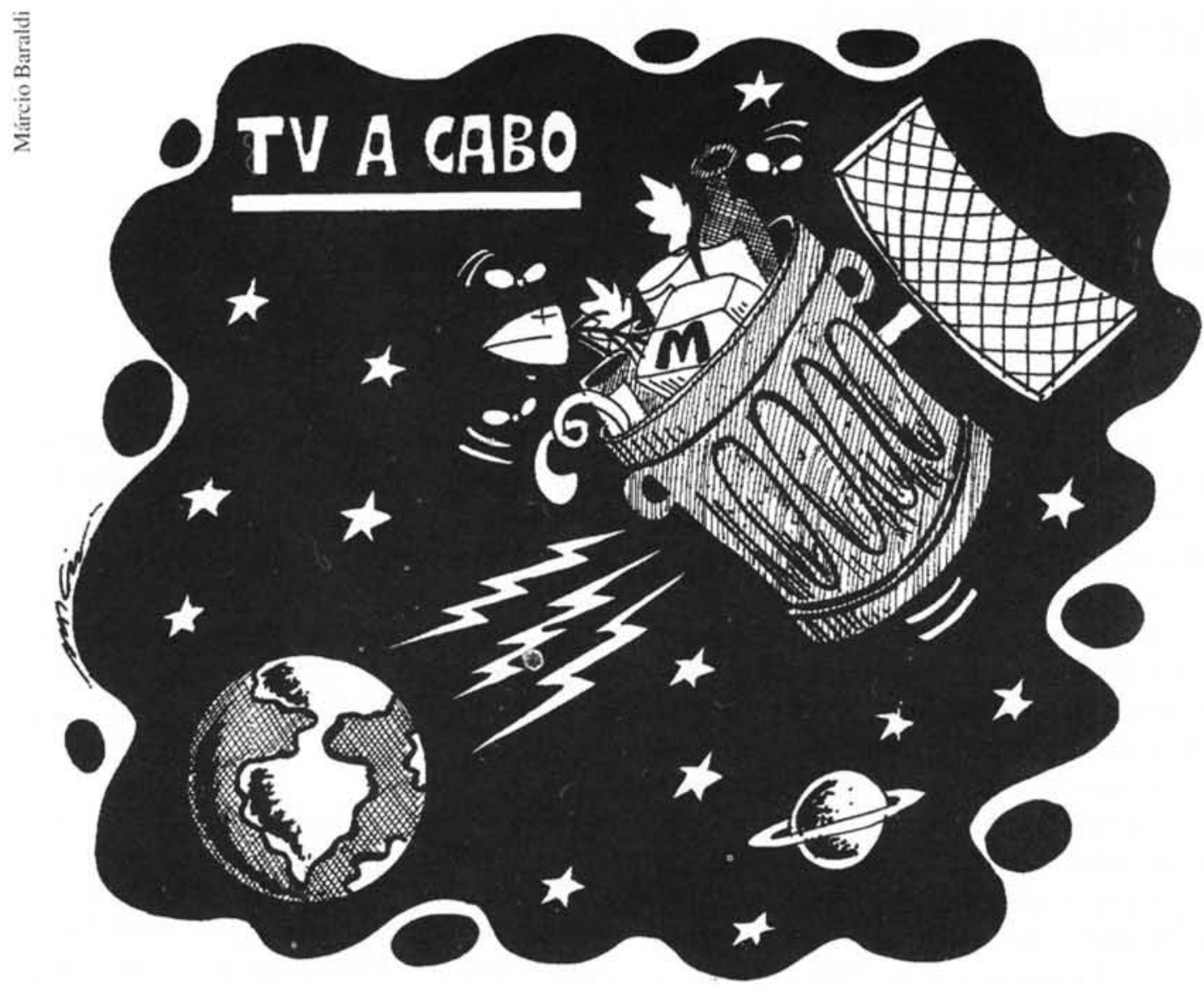

idéia de uma TV paga, e, last but not least (por último, mas não menos importante), a produção brasileira.

$O$ aumento do oferecimento de canais (são mais de 40, contra sete na TV aberta) nem longinquamente se reflete no aumento do espaço para o produtor brasileiro. É uma relação perversa. As poucas redes que se arriscam a investir no produto independente têm que aproximar seus custos do que é praticado no mercado.
E compra-se programação importada quando se compra - a até US\$ 100 a hora. Com a chegada da transmissão direta por satélite na banda $\mathrm{Ku}^{2}$, já a partir do próximo mês, a urgência desta avaliação se torna maior.

Serão 140 canais em dois sistemas, chegando a 300 em um ano. Corre-se o sério risco de ter lixo multiplicado mais uma vez, afrontando as possibilidades de diversificação oferecidas pela tecnologia.

Toda essa distorção não é um privilégio brasileiro. Internacionalmente, sa-

2. Banda Ku é um sistema de transmissão de alta frequência, feita através de satélite, e permite que seus sinais sejam captados por antenas parabólicas de apenas $60 \mathrm{~cm}$. (N.E.) 
be-se que Rupert Murdoch oferece até US\$ 3 milhões por um espaço para seu canal de notícias, além de distribuí-lo de graça para a operadora por dois, três, até cinco anos.

E, no entanto, não é para serem receptadoras de banditismo que foram criadas as operadoras. Elas são hoje para o mercado o que as grandes redes abertas eram nos anos 70 e 80. Por isso, têm a obrigação de exibir uma postura ética mais sadia.

A equação é complexa e portanto difícil de resolver. Por um lado, há no Brasil um mercado engatinhante, de 1,5 milhão de assinantes, que gera US\$ 60 milhões por mês para as operadoras - US\$18 milhões dos quais são repassados para as programadoras. Destes US\$ 18 milhões, mais da metade vai para os canais que supostamente alavancam as vendas dessas assinaturas (filmes e esportes). A fatia que sobra para mais de 30 canais é mesmo muito pequena.

Há um ano, o número de assinantes era de apenas 50 mil. Eles serão 7 milhões em 1999. Em três anos, o mercado de TV por assinatura no Brasil estará gerando mais de US\$ 250 milhões por mês, o que vem a ser, por exemplo, o faturamento de uma rede do tamanho do SBT durante todo o ano de 1995.

Um mercado deste tamanho é incompatível com os telehits da vida, que hoje, na prática, ocupam mais de $50 \%$ da programação dos programadores. É urgente que se impeça que a sociedade se acostume com isso, como se acostumou com o pérfido sistema das grandes redes.

$\mathrm{O}$ iminente barateamento do custo do satélite - privatizado dentro de dois anos vai facilitar ainda mais a produção e distribuição de programas de televisão de boa qualidade no Brasil.
Não é razoável supor que o espaço para isso esteja ocupado pelo entulho audiovisual de todo o mundo. Uma nova televisão está surgindo e são poucos os que ainda imaginam que a sua economia seja marginal. A espinha dorsal desta nova televisão está no oferecimento de programação. É a inteligência que move esta oferta, mas o mercantilismo e a burocracia já são amplamente hegemônicos sobre ela.

\section{EXIGÊNCIA PATÉTICA}

A televisão por assinatura no Brasil corre o sério risco de seguir o modelo da televisão aberta. É o pior caminho que poderia escolher. As autoridades americanas, numa rara ingerência sobre as decisões do setor privado, saíram em defesa do público - e o tempo vai rapidamente mostrar que elas acabaram agindo em favor da integridade do veículo.

Aqui, a legislação específica prevê apenas uma patética exigência de reserva de canais para o Estado e a distribuição de um canal brasileiro, se houver. Mesmo este canal acabou sendo discutido à luz do corporativismo dos produtores de cinema, que têm uma histórica capacidade de mobilização e fazem muito bem em tentar segurar uma fatia do mercado - mas não beneficiam em nada a formação de uma indústria de televisão.

O espectador brasileiro está em vias de ser convidado a assinar sistemas que levem para suas casas, em grande quantidade, o que de pior se produz na televisão internacional, apenas porque isso fica mais barato e a abrir mão de uma televisão segmentada e pluralista, em favor da estupidez exponencializada. Da resposta do espectador a esse convite depende a saúde financeira do mercado. 
Da ocupação consistente de centenas de canais, por outro lado, depende o vigor intelectual da televisão como veículo e a sedimentação de uma nova indústria brasileira de produção audiovisual que seguidamente

Resumo: A programação internacional oferecida pelas grandes redes de canais por assinatura é de baixissima qualidade e chega praticamente de graça às empresas operadoras, em detrimento da real segmentaçāo; da produçāo brasileira e de uma programaçāo pluralista de qualidade. A exemplo da programação dos canais abertos, o assinante não conta, ainda, com qualquer controle ou fiscalização.

Palavras-chaves: TV por assinatura, operadoras, canais, mercado, programação dá mostras de estar entre as melhores do mundo.

A sociedade vai decidir agora o que será este veículo, esta cultura e esta indústria nos próximos 50 anos.

Abstract. The international programming offered by the large cable TV networks is of a very lead quality and it costs almost nothing to the firms to the detriment of the real segmentation of Brazilian production and of a pluralist programming of higt quality. Just like the programming of ordinary channels, the subscriber still doesn't have any control or fiscalization.

Key-words: cable TV, firms, channels, marketplace, programs 